\title{
Comunidade de Prática de Professores que Ensinam Matemática como Espaço de Negociações de Significados sobre a Resolução de Problemas
}

\author{
Teachers' Community of Practice as a Space of Negotiation of \\ Meaning on Problem Solving
}

Wanusa Rodrigues Ramos*

Ana Lúcia Manrique ${ }^{* *}$

\begin{abstract}
Resumo
Neste artigo, apresentamos resultados de uma pesquisa que teve como objetivo investigar negociações de significados envolvendo a estratégia de ensino Resolução de Problemas, ocorridas em um grupo de professores e futuros professores que ensinam Matemática. Utilizamos o conceito de Comunidade de Prática (WENGER, 2001) para analisar em que medida um grupo de professores e futuros professores se configura como um espaço de negociações de significados, por meio da interação entre os processos de participação e reificação. Selecionamos episódios de encontros do grupo nos quais a Resolução de Problemas esteve presente e pontuamos, em nossa análise, negociações de significados que contribuíram com o processo formativo dos professores e futuros professores, que abordaram o papel do professor e dos alunos, a elaboração de atividades e concepções da Resolução de Problemas. As negociações de significados ocorreram em momentos de discussão, de reflexão e de compartilhamento de experiências sobre práticas de sala de aula.
\end{abstract}

Palavras-chave: Formação de Professores. Comunidades de Prática. Resolução de Problemas. Educação Matemática.

\begin{abstract}
This article presents results of a research that analyzed negotiation of meaning on Problem Solving that took place in a group of teachers and future mathematics teachers. We use the concept of Community of Practice (Wenger, 2001) to analyze as a group constituted how a teachers' Community of Practice can be configured as a space for negotiation of meaning, considering the interaction between participation and reification processes. Episodes of meetings, which explain discussions on the subject, were chosen and the analysis indicated that there were negotiation of meaning that contributed to the process of teacher education and education of future teachers, which addressed the role of the teacher and students, the development of activities, and conceptions of Problem Solving. The negotiations of meaning occurred in moments of discussion, reflection and sharing of experiences on classroom practices.
\end{abstract}

Keywords: Teacher Education. Communities of Practice. Problem solving. Mathematics Education.

\footnotetext{
* Doutoranda do Programa de Estudos Pós-Graduados em Educação Matemática da Pontifícia Universidade Católica de São Paulo (PUC-SP). Docente da Rede Municipal de Ensino de São Paulo, São Paulo, Brasil. Endereço para correspondência: Rua Coqueiral, 17, Jardim Itápolis, CEP 03942-030, São Paulo, São Paulo, Brasil.E-mail: wanusa_rodrigues@ hotmail.com

${ }^{* *}$ Doutora em Psicologia da Educação pela Pontifícia Universidade Católica de São Paulo (PUCSP). Docente do Programa de Estudos Pós-Graduados em Educação Matemática da Pontifícia Universidade Católica de São Paulo (PUC-SP), São Paulo, São Paulo, Brasil. Endereço para correspondência: Rua Marquês de Paranaguá, 111, Consolação, CEP 01303-050, São Paulo, São Paulo, Brasil. E-mail: manrique @ pucsp.br.
} 


\section{Introdução}

No presente artigo, apresentamos os resultados de uma pesquisa que teve como objetivo investigar negociações de significados envolvendo a Resolução de Problemas que ocorreram em um grupo de professores e futuros professores que ensinam Matemática, com características de uma Comunidade de Prática, inserido no contexto da política pública do Programa Observatório da Educação (Obeduc/Capes).

O grupo está inserido no projeto em rede aprovado no Edital 049/2012/CAPES/INEP, intitulado: Rede Colaborativa de práticas na formação de professores que ensinam matemática: múltiplos olhares, diálogos e contextos, que propõe a criação de uma rede colaborativa entre três Programas de Pós-Graduação que possuem características distintas, sob a coordenação geral do Programa da Educação da Universidade Federal de São Carlos, campus de Sorocaba (UFSCAR-Sorocaba), e com núcleos locais no Programa da Educação Matemática da Pontifícia Universidade Católica de São Paulo (PUC-SP) e no Programa Ensino, História e Filosofia das Ciências e Matemática da Universidade Federal do ABC (UFABC).

O projeto apresenta como objetivo geral compreender, problematizar e evidenciar o potencial da rede de colaboração entre práticas de ensino, pesquisa e extensão no processo de constituição profissional do professor que ensina matemática. Busca, também, compreender como se estabelece o processo de formação do professor ao longo da vida, em especial na etapa de inserção à docência e quais suas implicações.

Nossa atenção, neste artigo, se volta ao núcleo da PUC-SP e aos processos formativos ocorridos nesse grupo, formado por professores de escolas públicas e futuros professores que se aproximaram dessa Universidade buscando complementação da formação inicial e formação continuada. A proposta desse núcleo busca superar modelos de cursos para docentes pautados em palestras e treinamentos e entende que espaços que reúnem acadêmicos e professores possuem um grande potencial formativo, por agregar diferentes olhares e experiências sobre o processo de ensinar/aprender matemática.

Por esse motivo, defendemos que projetos desenvolvidos no Programa Obeduc podem apresentar possibilidades diferenciadas de formação de professores, pois configuram-se como espaços formativos que permeiam a formação inicial e a continuada.

O grupo que observamos é composto por professoras pesquisadoras e estudantes de mestrado e doutorado do Programa de Pós-Graduação em Educação Matemática da PUC-SP, estudantes de graduação em Pedagogia e Licenciatura em Matemática de outras Instituições, 
professores dos anos iniciais e professores de matemática dos anos finais do ensino fundamental de escolas públicas de São Paulo.

Trata-se, portanto, de um grupo que foi intencionalmente constituído, pelas duas professoras pesquisadoras do grupo Obeduc - núcleo PUC-SP, por sujeitos em diferentes momentos da trajetória profissional, visando a formação e o desenvolvimento profissional de todos.

Consideramos o conceito de Comunidade de Prática - CoP (LAVE; WENGER, 1991; WENGER, 2001) para analisar as negociações de significados acerca da Resolução de Problemas que ocorreram no interior desse grupo. Nessa perspectiva, a aprendizagem é concebida como decorrência da participação em práticas sociais, em particular pela participação em Comunidades de Prática. Esta é a nossa lente teórica para apresentar episódios das interações e nossas reflexões sobre esse processo.

\section{Comunidades de Prática e Formação de Professores}

Embora não seja resultado de estudos sobre educação, a Teoria Social da Aprendizagem e o decorrente conceito de Comunidade de Prática (LAVE; WENGER, 1991; WENGER, 2001) têm se mostrado, nos últimos anos, ferramentas oportunas para estudos relacionados à formação de professores e estão sendo cada vez mais utilizados por pesquisadores de diversos países.

Wenger, McDermott e Snyder (2002, p. 4) foram os pioneiros em usar o termo Comunidades de Prática. Eles salientam que:

Comunidades de prática são grupos de pessoas que compartilham uma preocupação, um conjunto de problemas, ou uma paixão a respeito de algum tópico, e que aprofundam seu conhecimento e expertise nesta área, interagindo de forma permanente $^{1}$.

Portanto, uma CoP é formada por pessoas que têm um interesse comum e desejam partilhar e aprofundar seus conhecimentos. Os membros de uma Comunidade de Prática estão engajados em aprender juntos e compartilhar novos conhecimentos que podem repercutir nas práticas do grupo:

Com o tempo, essa aprendizagem coletiva conduz a práticas que refletem tanto a busca de nossos empreendimentos como as relações sociais que as acompanham. Portanto, estas práticas são a propriedade de um tipo de comunidade criada, com o tempo, mediante a busca sustentada de um empreendimento compartilhado. Por isso

\footnotetext{
${ }^{1}$ Tradução de Moser (2010, p. 211).
} 
faz sentido chamar de comunidades de prática a este tipo de comunidades. ${ }^{2}$

(WENGER, 2001, p. 69, tradução nossa)

Wenger (2004, p. 3) caracteriza uma Comunidade de Prática mediante a existência de um domínio, uma comunidade e uma prática. $\mathrm{O}$ domínio refere-se à área de conhecimento que reúne a comunidade, dá a ela sua identidade e define as questões chave que a comunidade precisa abordar. A comunidade refere-se ao grupo de pessoas para quem o domínio, a qualidade das relações entre os membros e a definição de fronteira entre o interior e o exterior são relevantes. E a prática refere-se ao corpo de conhecimentos, métodos, ferramentas, histórias, casos, documentos que os membros da comunidade compartilham e desenvolvem em conjunto.

No que se refere à utilização desse referencial na formação de professores, as Comunidades de Prática têm se constituído, nos últimos anos, em um espaço promissor para o desenvolvimento de pesquisas que busquem compreender os processos formativos de grupos de professores e futuros professores (BELINE, 2012; NAGY, 2013; RAMOS, 2015).

Cyrino (2009, p. 106) aborda esta questão ao afirmar:

A emergência de comunidades de prática em cursos de formação de professores, em particular nos que discutem metodologia, desempenho e atitudes de professores, podem fazer a diferença na investigação sobre como esse envolvimento possibilita a aprendizagem desses profissionais.

No entanto, o levantamento que realizamos nos mostrou que pesquisas que relacionam Comunidades de Prática com formação dos professores que ensinam matemática ainda são poucas e revelam um campo fértil a ser explorado por pesquisadores em Educação Matemática, podendo trazer ricas contribuições para o cenário da formação de professores que ensinam Matemática.

\section{0 processo de negociação de significado}

Para Wenger (2001, p. 78), viver é um processo constante de negociação de significado. É por meio desse processo que experimentamos o mundo e o nosso engajamento nele como algo significativo. Ele nos explica que o conceito de negociação, muitas vezes, é utilizado como sinônimo de acordo entre duas ou mais pessoas, mas elucida que seu propósito

\footnotetext{
2 “Con el tempo, este aprendizaje colectivo desemboca en unas prácticas que reflejan tanto la búsqueda del logro en nuestras empresas como las relaciones sociales que la acompañan. Por lo tanto, estas prácticas son la propiedad de un tipo de comunidad creada, con el tempo, mediante la intención sostenida de lograr una empresa compartida. Por ello tiene sentido llamar comunidades de práctica a esta clase de comunidades" (WENGER, 2001, p. 69).
} 
em utilizar o termo negociação é transmitir "[...] a ideia de uma interação contínua, de uma conquista gradual e de um processo de dar e receber"33 (tradução nossa).

Nesse sentido, o processo de negociação de significados é dinâmico e sempre gera novas circunstâncias para posteriores negociações e significados, ao mesmo tempo em que o significado não existe em nós nem no mundo, e, sim, em uma relação dinâmica de viver no mundo (WENGER, 2001)

Esse autor argumenta que a negociação de significado pressupõe a interação entre dois processos: a participação e a reificação. E utiliza o termo participação como sendo

[...] a experiência social de viver no mundo do ponto de vista da afiliação a comunidades sociais e da intervenção ativa em empreendimentos sociais. Neste sentido, a participação é tanto pessoal como social. É um processo complexo que combina fazer, falar, pensar, sentir e pertencer. Intervém em toda a nossa pessoa, incluindo corpo, mente, emoções e relações sociais ${ }^{4}$ (WENGER, 2001, p.80, tradução nossa)

Percebemos, assim, o caráter social que o autor atribui à participação. A participação em comunidades de prática está ligada à nossa experiência de vida, sendo importante ressaltar que:

- A participação não equivale à colaboração, mas pode supor todo tipo de relações, harmoniosas ou conflituosas;

- A participação em comunidades sociais dá forma às nossas experiências e também dá forma às comunidades;

- A participação é mais ampla que o simples engajamento na prática. Vai além da intervenção direta em atividades específicas. Coloca a negociação de significados no contexto das nossas formas de afiliação a várias comunidades.

Nossa participação é o que dá sentido às nossas experiências. É por meio dela que nos envolvemos nos processos de negociação de significados empreendidos pela prática da comunidade. Nessa concepção, a participação é apontada, com frequência, como uma fonte de identidade, pois““[...] nossas relações com comunidades de prática supõem ao mesmo tempo participação e não participação, e nossas identidades são constituídas pela combinação das duas", (WENGER, 2001, p. 205, tradução nossa)

\footnotetext{
3 “[...] la idea de una interacción continua, de un logro gradual y de un proceso de toma y daca." (WENGER, 2001, p. 78)

4 “ [...] la experiencia social de vivir en el mundo desde el punto de vista de la afiliación a comunidades sociales y de la intervención activa en empresas sociales. En este sentido, la participación es tanto personal como social. Es un proceso complejo que combina hacer, hablar, pensar, sentir y pertenecer. En él interviene toda nuestra persona, incluyendo cuerpo, mente, emociones y relaciones sociales.” (WENGER, 2001, p. 80)

"[...] nuestras relaciones con comunidades de práctica suponen al mismo tiempo participación e no participación y nuestras identidades están conformadas por combinaciones de las dos" (WENGER, 2001, p. 205)
} 
Por esse motivo, Wenger (2001) apresenta as diferentes formas de participação que podem ocorrer em uma Comunidade de Prática, elencando-as em quatro categorias principais:

[...] a participação plena (pessoa própria), não participação plena (pessoa de fora), periférica (participação possibilitada pela não participação, independentemente de conduzir a uma participação plena ou permanecer em uma trajetória periférica) e marginal (participação limitada pela não participação, independentemente de conduzir a uma não participação ou a uma posição marginal ${ }^{6}$ (WENGER, 2001, p. 208, tradução nossa).

As diferentes formas de participação em uma Comunidade de Prática estão relacionadas, pois uma experiência de participação periférica pode conduzir à participação plena, como membro reconhecido no interior da comunidade, ou a uma continuidade de participação periférica, e da mesma forma, a marginalidade pode conduzir a uma continuidade de participação marginal ou para o seu exterior, em que a pessoa não mais pertence à comunidade.

O segundo processo relacionado à negociação de significado em uma Comunidade de Prática é a reificação. Wenger (2001) descreve a reificação como o processo de dar forma a nossa experiência, produzindo objetos que refletem esta experiência em coisa, e afirma que tal processo é fundamental para toda prática, pois toda comunidade produz abstrações, instrumentos, símbolos, relatos, termos e conceitos que reificam algo da prática de uma forma sólida. Motivo pelo qual a reificação envolve uma gama de processos que incluem fazer, desenhar, representar, nomear, codificar e descrever, além de perceber, interpretar, utilizar, reutilizar, decifrar e reestruturar, e ocupa grande parte da energia coletiva da comunidade e dá forma à sua experiência.

Wenger (2001) faz referência aos processos de participação e reificação em uma condição de dualidade ${ }^{7}$ para a negociação de significado. Nessa interação, participação e reificação são, ao mesmo tempo, distintas e complementares.

\section{0 encaminhamento da pesquisa}

A fim de responder à questão norteadora de nossa pesquisa: que negociações de significados envolvendo Resolução de Problemas ocorreram na Comunidade de Prática do

\footnotetext{
6 “" [...] la plena participación (persona propia), la plena no participación (persona ajena), la periferia (participación posibilitada por la no participación, independientemente de que conduzca a una participación plena o permanezca en una trayectoria periférica) y la marginalidad (participación limitada por la no participación, independientemente de que conduzca a una no afiliación o a una posición marginal)" (WENGER, 2001, p. 208)

7 Wenger (2001) utiliza o termo dualidade como uma só unidade conceitual formada por dois elementos inseparáveis e mutuamente constitutivos.
} 
grupo Obeduc - núcleo da PUC-SP?, utilizamos, como instrumentos para a coleta dos dados, transcrições de gravações em áudio de reuniões realizadas pelo grupo Obeduc - núcleo da PUC-SP, diário de campo com anotações feitas durante e depois de cada encontro, e observação participante.

Analisamos episódios ocorridos nos encontros do grupo, no segundo semestre de 2013, configurando-se como um empreendimento sobre o qual a comunidade dispensou grande parte de sua atenção e engajamento.

Os encontros do grupo Obeduc, núcleo da PUC-SP, foram, em sua maioria, gravados em áudio. Realizamos uma escuta inicial de todas as gravações em áudio para selecionarmos apenas os encontros que forneceriam dados para nosso estudo. Desse modo, após a primeira escuta, identificamos que as discussões que nos interessavam estavam concentradas no $2^{\circ}$ semestre de 2013.

Tomando por base esse direcionador, antes de realizar as transcrições, realizamos uma segunda escuta das gravações dos encontros em que a Resolução de Problemas foi discutida. Como os encontros duravam, em média, três horas, realizamos a transcrição apenas dos momentos em que as discussões estavam atreladas à Resolução de Problemas. Ou seja, desses encontros excluímos, por exemplo, os momentos em que houve discussões sobre calendário, organização do grupo, justificativas de ausências, congressos e eventos, ou quando ocorreram conversas paralelas.

De posse das transcrições, selecionamos os episódios e iniciamos nosso processo de análise interpretativa, buscando descrever as negociações de significados acerca da Resolução de Problemas ocorridas no interior do grupo Obeduc, núcleo da PUC-SP.

Quanto ao diário de campo, ele foi organizado de modo a conter informações descritivas sobre as dinâmicas assumidas pelo grupo, bem como reflexões sobre as discussões ocorridas durante os encontros, sempre que isso fosse possível, ou seja, procuramos, com esse instrumento, contemplar uma dupla perspectiva: uma descritiva e outra interpretativa (FIORENTINI; LORENZATO, 2012).

Não adotamos uma grade fechada para fazer as anotações. Realizamos as observações de forma espontânea e com o intuito de evidenciar aspectos que não aparecem explicitamente nos diálogos, como reações dos participantes do grupo diante de negociações. Esse instrumento foi fundamental na escolha dos episódios que analisamos, já que indicou, conforme percepção dos observadores, momentos em que houve engajamento dos integrantes do grupo nos empreendimentos e ações. 
Adotamos, também, a observação de todos os encontros do grupo Obeduc, núcleo PUC-SP, como um procedimento metodológico para a coleta de dados. No caso do nosso estudo, realizamos uma observação não estruturada e participante, uma vez que não estabelecemos a priori um roteiro de observação, além do fato de os observadores terem participado como membros do grupo, interagindo com os demais. Sobre esse aspecto, Vianna (2007, p. 33) pontua que, no caso da observação participante, o observador não é apenas um pesquisador, ele próprio é também um sujeito da pesquisa.

Assim, é importante pontuarmos que os observadores apresentaram-se, desde o início dos encontros, como integrantes do grupo. Além disso, todos os participantes do grupo Obeduc, núcleo da PUC-SP, assinaram uma declaração de consentimento livre e esclarecido quanto à participação no projeto, concordando em que os dados coletados fossem utilizados para fins de pesquisa.

Com relação aos professores e futuros professores participantes do grupo, vale salientar que o edital no 049/2012/CAPES/INEP estabeleceu, para cada um dos núcleos do projeto em rede do Obeduc, a seleção de seis professores da rede pública de ensino e seis estudantes de graduação.

Para a constituição do grupo Obeduc, núcleo da PUC-SP, foram abertos editais públicos de seleção, tanto para professores quanto para estudantes de graduação, que tiveram ampla divulgação em todos os campi da universidade, bem como em outras IES que possuíam cursos de Licenciatura em Matemática e Pedagogia na cidade de São Paulo. O processo de seleção incluiu análise do currículo e entrevista dos interessados.

Procurando privilegiar um grupo heterogêneo, a escolha dos participantes, feita intencionalmente pelas duas professoras pesquisadoras, incluiu tanto professores dos anos iniciais como professores de Matemática dos anos finais do ensino fundamental, e estudantes de graduação dos cursos de Licenciatura em Matemática e Pedagogia. Consideramos que, com esse formato, seria possível contemplar uma das premissas estabelecidas no desenho original do projeto, que são os múltiplos olhares, de profissionais de formações distintas e em diferentes momentos da carreira.

Com o objetivo de manter o anonimato dos integrantes denominamos de:

a) PAI: os professores dos anos iniciais do ensino fundamental

b) $P A F$ : os professores de matemática dos anos finais do ensino fundamental

c) $A M:$ os estudantes do curso de Licenciatura em Matemática

d) $A P:$ os estudantes do curso de Pedagogia 
O grupo também era composto por quatro mestrandos e dois doutorandos. Nos episódios em que aparecem falas desses estudantes, vamos indicá-las com as siglas Mest ou Dout, respectivamente.

O grupo iniciou suas atividades em junho de 2013, e a dinâmica do trabalho desenvolvido durante os encontros foi estabelecida e negociada em conjunto e caminhou no sentido do que é descrito por Fiorentini (2013, p. 56):

$\mathrm{Na}$ colaboração, todos trabalham conjuntamente ("co-laboram") e se apoiam mutuamente, visando atingir objetivos comuns negociados pelo coletivo do grupo. $\mathrm{Na}$ colaboração, as relações, portanto, tendem a ser não hierárquicas, havendo liderança compartilhada e "co-responsabilidade" pela condução das ações.

Durante o segundo semestre de 2013, a comunidade concordou pelo engajamento mútuo no empreendimento de pesquisar e discutir sobre a estratégia da Resolução de Problemas. Nesse período foram realizados 10 encontros, sendo três em agosto, dois em cada um dos meses de setembro, outubro e novembro, e um encontro em dezembro. As atividades envolveram, inicialmente, a escolha do tema da Resolução de Problemas como estratégia de ensino. Depois, os membros do grupo realizaram apresentações sobre os levantamentos realizados sobre o tema escolhido, com discussões coletivas, para, posteriormente, selecionar um conteúdo matemático para elaboração de atividades, considerando a Resolução de Problemas como estratégia de ensino, que seriam desenvolvidas em sala de aula. Após socialização, discussão e reflexão das atividades propostas, os professores e licenciandos desenvolveram as atividades em sala de aula e as experiências foram relatadas, discutidas e refletidas nos encontros do grupo, núcleo da PUC-SP. Dessa forma, a coleta de dados para este artigo contemplou episódios selecionados desses encontros.

\section{Negociações de significados acerca da Resolução de Problemas}

A primeira ação negociada pelo grupo envolveu uma pesquisa individual sobre o tema Resolução de Problemas, para posterior discussão e reflexão. Algumas das referências consultadas pelos professores e licenciandos do grupo foram Polya (1978), Dante (2002), Onuchic (1999) e os PCN (BRASIL, 1997, 1998).

Os estudos foram iniciados por aspectos históricos da Resolução de Problemas, considerando que eles são essenciais para uma compreensão efetiva das tendências atuais da referida temática. Uma das primeiras discussões versava sobre as possíveis abordagens dadas à Resolução de Problema. Onuchic (1999, p. 206) aponta três modos diferentes de abordar a Resolução de Problemas, baseando-se em Schroeder e Lester: “ensinar sobre resolução de 
problemas, ensinar a resolver problemas e ensinar matemática através da resolução de problemas".

Nas discussões e reflexões sobre Resolução de Problemas, realizadas nos encontros do grupo Obeduc, núcleo da PUC-SP, foram priorizados aspectos didáticos, evidenciados na conduta pedagógica do professor, procurando evidenciar implicações para a prática docente e analisar posturas didáticas que contribuem para a utilização da Resolução de Problemas em sala de aula de Matemática.

Esse empreendimento configurou um momento que demandou a participação de todos, embora alguns tenham participado de forma mais plena e outros de forma mais periférica (WENGER, 2001). As discussões e reflexões realizadas no grupo podem ser evidenciadas pelo episódio a seguir

AM3: Eu achei interessante que muitos problemas matemáticos na verdade surgiram das necessidades das pessoas, de problemas do cotidiano que as pessoas precisavam se mobilizar para resolver. Eles não surgiam "do nada".

$[\ldots]$

PAF2: Quando eu estudei a Teoria das Situações Didáticas, eu percebi que, ao invés de nós partirmos do conceito matemático para chegar no problema, nós podemos partir de um problema para chegar no conceito matemático. É o sentido contrário do que estamos acostumados a fazer.

PAF1: Eu concordo com você. Porque é isso mesmo que nós fazemos, na maioria das vezes. Explicamos um conteúdo, passamos alguns exemplos e em seguida os exercícios e os problemas. Mas, eu acho que isso não é Resolução de Problemas, o que nós costumamos passar são situações-problema (ENCONTRO 17/08/13).

Percebemos, pelo episódio anterior, que as respostas de PAF1 e PAF2, professores especialistas de Matemática, sugerem que eles trabalham em uma perspectiva diferente das discutidas no grupo, aludindo a um padrão de professor de Matemática que é normalmente reproduzido, cuja estratégia é partir do conteúdo, passar exemplos e, em seguida, os exercícios de aplicação. Portanto, para iniciar um trabalho com Resolução de Problemas, entendemos que se torna necessário superar esse modelo de professor e da forma de conduzir as atividades nas aulas de Matemática. Perspectiva segundo a qual a Resolução de Problemas "passa a ser pensada como uma metodologia de ensino, como um ponto de partida e um meio de se ensinar matemática" (ONUCHIC, 1999, p. 207).

Alguns membros da comunidade manifestaram ter dúvidas quanto ao trabalho com a Resolução de Problemas e apontaram, diversas vezes, a necessidade de aprofundar as discussões e, além disso, vivenciar uma experiência com os alunos em que pudessem utilizar o que estavam discutindo:

PAI3: Eu percebo que preciso compreender melhor como trabalhar com a Resolução de Problemas, porque nós conversamos muito sobre isto aqui, e eu faço tanta coisa em sala de 
aula, mas será que eu estou aplicando a Resolução de Problemas? Então eu preciso compreender primeiro isto [...].

AM3: Para mim, antes de eu fazer as leituras, eu achava que qualquer problema fazia parte da Resolução de Problemas, e eu descobri que não, porque aqueles problemas que o aluno já tem a resposta de cara, que já tem a resolução de cara, não é Resolução de Problemas. Eu achava que eu trabalhava com resolução de problemas.

PAI1: Nós lemos alguns textos sobre a Resolução de Problemas aqui, nós discutimos, e acho que este movimento foi muito legal. Mas, ainda fico pensando como será quando formos propor alguma atividade em sala de aula, porque percebo que não é tão simples assim (ENCONTRO 03/08/13).

Entendemos que essas falas são reveladoras, por demonstrarem o desejo coletivo de dedicar mais tempo e energia do grupo em compreender e desenvolver atividades que envolvessem a Resolução de Problemas. O planejamento de uma atividade, elaborada a partir dessa estratégia de ensino, com um problema a ser proposto como fio condutor da aprendizagem, foi validado como parte importante da prática social do professor que ensina Matemática.

Assim, os membros do grupo perceberam que a Resolução de Problemas possui concepções que foram evoluindo ao longo do tempo, considerando as primeiras ideias de Polya (SILVA; SCHIRLO, 2014).

De modo que as negociações de significados ocorridas durante esse percurso de socialização das pesquisas, bem como as discussões realizadas, foram fundamentais para o entendimento que o grupo passou a construir a respeito da Resolução de Problemas e que, posteriormente, passou a fazer parte de seu repertório compartilhado. Podemos verificar essa negociação no episódio a seguir, entre um professor dos anos iniciais, um professor dos anos finais e um doutorando do grupo.

PAI2: Eu entendi que trabalhar com a Resolução de Problemas tem a ver, não só com o problema em si, mas como o professor vai lidar com as questões, como vai fazer com que os alunos lidem com isso. Então, por exemplo, se eu escrever na lousa "Problemas de multiplicação" e passar dez problemas, não tem desafio nenhum, mas se eu colocar "Problemas", mas proporcionar que eles possam descobrir, que eles resolvam, é diferente, na verdade, é a nossa postura, muito além do problema. A maneira como propomos é que deve ser problematizadora.

Dout2: Sim, o trabalho com a Resolução de problemas requer uma postura investigativa tanto do professor quanto do aluno. Os papéis são diferentes daqueles que estamos acostumados.

PAF2: A gente pode colocar como uma das concepções, ao invés de eu passar um conteúdo para depois passar um problema para o aluno resolver, para ver se ele entendeu. Fazer o contrário, eu passo um problema para o aluno resolver, ele vai ter que buscar uma maneira e meio que sem querer, ele vai chegar no conteúdo que eu quero ensinar. E nas diferentes resoluções surgirão outros conteúdos (ENCONTRO 31/08/13).

O entendimento sobre Resolução de Problemas, que seria compartilhado pelo grupo, foi sendo construído com o tempo, ou seja, esse significado foi negociado e renegociado pelo 
grupo em diversos encontros, e a negociação se deu pelo confronto de ideias, pelas participações e reificações.

Quando os professores e licenciandos refletiram sobre práticas docentes com Resolução de Problemas, ou seja, sobre como ensinar Matemática através da Resolução de Problemas, começaram a apontar diversas dificuldades que enfrentam em salas de aula. $\mathrm{O}$ episódio a seguir evidencia tais dificuldades.

PAF3: Uma coisa interessante nessa discussão é que o aluno precisa ter alguns conhecimentos anteriores para conseguir resolver o problema. E aí eu paro e penso: até que ponto eu dar um problema para que o aluno desenvolva por si só, somente com o conhecimento que ele tem, eu vou atingir quantos alunos na minha turma? Porque, querendo ou não, a gente tem problemas para trabalhar com a Resolução de Problemas na aula de Matemática: quantidade de alunos em sala de aula, muitos alunos com aprendizados diferentes, com níveis diferentes que estão na mesma sala. Por isso, muitas vezes a gente vai lá e passa exercícios para que ele reproduza, porque querendo ou não, é um método mais rápido e que a gente atinge uma quantidade maior de alunos. Em algumas vezes, eu tentei propor resolução de problema na minha sala, não sei se eu fiz certo, porque agora eu estou tendo mais conhecimento, eu atingi alguns poucos, eu posso dizer que só uns cinco alunos conseguiram elaborar, desenvolver e criar alguma estratégia. Os outros, muitos nem chegaram perto, mesmo com o conhecimento que eles têm. Então, eu acho positivo, não estou dizendo que é ruim, mas ao mesmo tempo, eu penso nas dificuldades, não querendo ser negativa, mas pensando na realidade.

PAII: Mas é bom ou é ruim ter alunos com níveis diferentes em sala de aula?

PAF3: Não sei se é ruim, é mais difícil, só isso. Aqueles que sabem mais podem ajudar os que sabem menos, podemos fazer atividades em grupo que criam também aquele espírito de colaboração, mas ao mesmo tempo é mais difícil.

PAF2: Quando estamos trabalhando Resolução de Problemas para ensinar um conteúdo, uma das partes fundamentais do trabalho é o erro dos alunos. Uma das primeiras coisas a trabalhar é "quebrar" isso, que os alunos só estão aprendendo se eles acertam. Na verdade, se passarmos um problema e todos errarem tudo, mas eles estão tentando desenvolver uma ideia e eles viram uma necessidade para aquilo, na hora em que viermos depois com o conteúdo em si, vai fazer mais sentido para eles. Num primeiro momento, a ideia é que eles errem mesmo e adquiram uma necessidade para determinado conteúdo, que será trabalhado, e aí eles terão uma aprendizagem ou não. Diferente da visão de trabalharmos um conteúdo, eles errarem, então eu que estou ensinando errado.

PAF3: Eu concordo com você, mas eu também vejo por um outro lado: a desmotivação. Muitos alunos se sentem desmotivados, não conseguem sair do lugar, ficam desanimados porque não conseguem fazer.

PAF2: Mas aí entra na questão que está presente nas leituras que a gente fez, que é a dificuldade do problema, a gente tem que ter uma média dessa dificuldade, não pode ser um problema difícil o suficiente para desmotivar, e nem fácil o suficiente para que ele consiga fazer de primeira.

PAF3: Mas a dificuldade varia de indivíduo para indivíduo. Pode ser que aquilo que é fácil para mim, seja muito difícil para o outro.

PAF2: Mas a ideia é essa mesma. Alguns alunos vão conseguir, e outros não (ENCONTRO 31/08/13).

No episódio transcrito, notamos que a PAF3 não se sentiu muito confortável com a ideia de trabalhar com a Resolução de Problemas e se manifestou quanto às dificuldades em obter algum resultado, argumentando que os alunos, em sua maioria, não têm os 
conhecimentos necessários para apresentar soluções para a proposta ou se sentem desmotivados diante dos problemas de Matemática. No entanto, suas declarações foram contrapostas pelo PAI1 e pelo PAF2. O PAI1 questionou a necessidade de os alunos estarem nos mesmos momentos de aprendizagem para que o professor possa realizar um trabalho com a Resolução de Problemas. Embora a PAF3 tenha concordado que não se trata de um aspecto negativo, ela permaneceu argumentando que isso torna o trabalho do professor mais difícil.

$\mathrm{Na}$ fala do PAF2, ele transparece o julgamento de que a PAF3 estava tendo um entendimento equivocado do que é trabalhar na perspectiva da Resolução de Problemas, por considerar que todos os alunos devem acertar. Ele argumenta sobre a importância do erro para a construção do conhecimento e da escolha de um bom problema, para que não seja fácil ou difícil demais, a ponto de desmotivar os alunos. Embora ambos (PAF2 e PAF3) sejam professores de Matemática experientes, eles demonstraram pontos de vista diferentes sobre o trabalho com a Resolução de Problemas. O PAF2 afirma, ainda, que as leituras realizadas pelo grupo o ajudaram na construção do seu entendimento, o que é um processo reificador.

Olhando para esse episódio, recordamos que Wenger (2001, p. 104, tradução nossa) alerta que em uma Comunidade de Prática as relações não são homogêneas, porque está permeada de relações entre pessoas que nem sempre pensam da mesma forma. Na verdade, a participação, tal como ele emprega o termo, não é equivalente à colaboração, mas pode supor todo tipo de relações, conflituosas ou harmoniosas, competitivas ou colaboradoras. Ele afirma, ainda, que

[...] a maioria das situações que supõem um compromisso interpessoal geram suas próprias tensões e conflitos [...] Os desacordos, os desafios e a competição podem ser formas de participação. E como forma de participação, a revolta é geralmente um sinal de maior compromisso do que a conformidade passiva ${ }^{8}$.

Deparar-se com uma opinião ou entendimento diferente, ou mesmo divergente, do que temos é potencialmente um fator que pode contribuir para produzirmos novos significados às nossas percepções, e isso pode ser ainda mais fértil em se tratando de um grupo heterogêneo, que apresenta múltiplos olhares e contextos.

Quando o grupo se comprometeu no empreendimento conjunto de desenvolver uma atividade na perspectiva da Resolução de Problemas, isto não supôs um acordo no sentido simples, de que todos acreditariam na mesma coisa ou estariam de acordo em tudo. Ao

\footnotetext{
8 "La mayoría de las situaciones que suponen un compromiso interpersonal generan sus propias tensiones y conflictos [...] Los desacuerdos, los retos y la competencia pueden ser formas de participación. Y como forma de participación, la rebelión suele ser señal de mayor compromiso que la conformidad pasiva" (WENGER, 2001, p. 104).
} 
contrário, as diferenças são produtivas no processo de negociação, à medida que fazem a comunidade avançar e desencadear novos empreendimentos.

Nesse processo de construção conjunta, ressaltamos que, em alguns momentos, não ficou evidente se os integrantes do grupo estavam se referindo a um problema ou a um exercício, conforme relato de um professor de Matemática dos anos finais:

PAF1: Eu tenho uns passinhos que eu sigo com os meus alunos. A primeira coisa é ler o enunciado, eu digo para eles irem grifando as informações que o enunciado traz. Aí eu vou resolvendo com eles. E eles vão utilizando os conhecimentos que já têm [...] Eles fazem os cálculos e no fim vem o principal, eles têm que verificar se o resultado que eles encontraram tem a ver com o que foi pedido (ENCONTRO 31/08/13).

Diante desse relato, entendemos que necessitávamos averiguar qual o entendimento que os membros do grupo tinham acerca dos dois conceitos. O episódio a seguir apresenta o questionamento proposto ao grupo:

Dout1: Mas, qual é a diferença entre problema e exercício?

AM1: No problema, a gente pensa. No exercício, a gente só reproduz.

PAI2: Isso me faz lembrar muito daqueles "exercícios de fixação", do tipo resolva. E o problema nos leva a pensar e a criar outras formas de obter uma resposta, e não uma só, fixa e fechada.

PAF2: O exercício, eu já sei como fazer. O problema, eu não tenho uma experiência anterior de como resolver. Eu vou construindo uma maneira, que pode ser a maneira que eu quiser.

Dout1: Então, o exercício, eu já sei o caminho, geralmente eu tenho um modelo e eu vou replicá-lo, eu já sei o percurso. Agora, o problema é mais abrangente, eu não sei o caminho, eu tenho $n$ possibilidades para resolver e chegar na solução. Qual dos dois é mais importante?

PAF2: Os dois. Um no sentido de construção do conhecimento e o outro no sentido de treino daquele conhecimento. Não adianta nós construirmos e depois não treinarmos, não fortalecermos aquele conhecimento. Nós aprendemos, mas se não treinarmos, com o tempo, vai se perdendo aquele conhecimento (ENCONTRO 29/09/2013).

O grupo entendeu, depois das reflexões e discussões sobre Resolução de Problemas, que os participantes deveriam vivenciar uma experiência prática de elaborar uma atividade dentro da perspectiva da Resolução de Problemas que o grupo Obeduc - núcleo PUC-SP tinha naquele momento e elegeu um conteúdo para iniciar o planejamento das atividades. Foi proposto que os participantes se dividissem em dois subgrupos. E, em um dos encontros, os subgrupos relataram as dificuldades que enfrentaram para planejar a atividade, conforme pode ser evidenciado no episódio a seguir.

PAF3: Eu não estava entendendo muito bem a ideia do grupo (subgrupo 1), depois eles me explicaram, eu estava levando para uma linha que não é a construção de um raciocínio, era mais o tradicional que eu sempre faço, e aí eles me ajudaram. Eu fui muito provocada, porque eu estava pensando nessa linha de não deixar o aluno construir, e eu estava pensando que estava deixando, e eles me mostraram que na verdade não, que eu já estava indicando o caminho, não deixando o aluno fazer por ele próprio. E eu achei que estava tudo bem, mas depois eu percebi.

AM1: Eu pude perceber o quanto é difícil construir um problema, problematizar. 
PAF1: É difícil construir um problema que envolva um conteúdo, é muito difícil nós mesmos inventarmos um problema que estimule os alunos a resolver, a querer construir. Eu sou muito técnica, eu sou muito do resolva.

AM3: Nossa maior dificuldade foi definir a meta, o que a gente queria.

PAI2: No nosso grupo (subgrupo 2) foi até bem rápido, na primeira sacada a gente já pensou, só que na conversa a gente descobriu que cada um entendeu uma coisa completamente diferente. Pensar a atividade foi rápido, o problema foi que a gente teve várias interpretações e resoluções para o que estava sendo proposto.

AM2: E foi muito interessante porque a gente percebeu que dá para construir várias situações, de acordo com o que cada um pensou. Todos estávamos compondo a mesma atividade, de pôr o aluno para pensar, de construir estratégias, mas cada um pensou de uma maneira diferente.

PAF2: O nosso grupo queria a mesma coisa, mas a questão é que havia quatro maneiras totalmente diferentes de resolver e de ensinar quatro coisas totalmente diferentes. Você vê que de uma atividade simples, você pode tirar várias coisas. E a discussão foi muito rica, porque um teve uma ideia, o outro acrescentou, e cresceu muito. A gente até pensou se era uma atividade ou uma sequência, porque tinha muita coisa para ser explorada, e mesmo se a gente não for usar nada disso, com certeza para os participantes ficaram mil ideias para trabalhar este assunto, foi muito amplo (ENCONTRO 31/08/13).

Os integrantes do subgrupo 1 pontuaram dificuldades em problematizar e construir uma proposta mais aberta. Ressaltaram que estão mais habituados a trabalhar com exercícios que colocam em prática técnicas de resolução, ao invés de provocar o aluno a construir uma estratégia de resolução. No entanto, não há problema se não existe um real desafio nem a necessidade de verificação para validar o processo de solução (ONUCHIC, 1999).

Parte da dificuldade em formular bons problemas se dá devido ao fato de que a prática mais frequente no ensino da Matemática ainda é aquela em que o professor apresenta o conteúdo oralmente, partindo de definições, exemplos, demonstração de propriedades, seguidos de exercícios de aprendizagem, fixação e aplicação, e pressupõe que o aluno aprende pela reprodução. Ainda é comum considerar que uma reprodução correta de exemplos e exercícios é evidência de que ocorreu a aprendizagem (BRASIL, 1997, 1998).

Já no relato do subgrupo 2, percebemos que eles enfrentaram uma dificuldade de natureza contrária ao subgrupo 1: como o problema era muito aberto, eles perceberam a necessidade de maior clareza na proposta, a fim de não gerar diversas interpretações entre os alunos, pois entre os próprios integrantes do subgrupo houve interpretações diversas sobre o mesmo problema.

Ainda, sobre o papel do professor frente a uma proposta de Resolução de Problemas, percebemos, no episódio a seguir, que os integrantes do subgrupo 1 interferiram na maneira como uma das professoras de Matemática dos anos finais, PAF1, estava conduzindo a atividade:

PAF3: A PAF1 explicava bastante. Eu falei pra ela: 'PAF1, fica quieta, você não tem que explicar, o problema está lá, deixa eles resolverem'. 
PAF1: Eu queria falar pra eles (subgrupo 2) que era para fazer o cálculo, mas eles (subgrupo 1) não deixavam eu abrir a boca [...].

Dout2: Há momentos em que o professor tem que fazer intervenções, sim, mas é preferível que sejam feitas na forma de perguntas (ENCONTRO 29/09/2013).

Nessa interação, percebemos a necessidade de uma redefinição do papel do professor no processo de construção do conhecimento. Ele não é mais aquele que expõe o conteúdo aos alunos, mas fornece as informações necessárias que o aluno não tem condições de obter sozinho, interage, questiona, contesta, confronta diferentes soluções, num processo de mediação entre o aluno e o conhecimento (ONUCHIC, 1999).

As diferentes formas de participação no interior do grupo Obeduc, núcleo PUC-SP, possibilitaram verificar que influenciamos e somos influenciados, de maneira mais ou menos intensa, no processo de negociação de significados.

De modo geral, pudemos perceber que os professores foram participantes mais ativos nas discussões, como membros plenos, ao passo que os estudantes de graduação participaram de forma mais periférica (WENGER, 2001). No entanto, a forma de participação que é mais periférica, por opção ou por necessidade, pode conduzir a uma trajetória de entrada na comunidade, proporcionando acesso à sua prática e sendo importante para a constituição de identidades. A legitimidade desses participantes é adquirida quando são tratados como membros potenciais que podem acessar a uma participação plena, que possibilita um compromisso real com a prática.

Em uma Comunidade de Prática, em que seus membros tenham compromisso mútuo com os empreendimentos desenvolvidos em seu interior, todos aprendem maneiras de participar e de construir significados sobre o mundo e com o mundo, na interação com outras pessoas. É no trabalho conjunto e na interação com o outro que constituímos nossas identidades e que a comunidade desenvolve sua trajetória e sua história (WENGER, 2001).

\section{Algumas considerações}

Considerando que nosso objetivo era investigar negociações de significados que ocorreram quanto à Resolução de Problemas no grupo Obeduc, núcleo PUC-SP, selecionamos encontros em que a discussão sobre a temática esteve presente e pontuamos, em nossa análise, negociações de significados sobre o papel do professor e dos alunos, sobre a elaboração de atividades e acerca das concepções da Resolução de Problemas, que contribuíram com o processo formativo dos professores e futuro professores. 
O processo de conhecer e aprender como trabalhar com a estratégia de Resolução de Problemas foi considerado pelo grupo como parte importante da prática social do professor que ensina Matemática. Ou seja, os membros da comunidade manifestaram o interesse não só em se apropriar de forma mais aprofundada da temática, mas de transformar a participação em processos educativos, no sentido de adotar a prática como elemento desencadeador de aprendizagens.

Nesse sentido, participar de uma Comunidade de Prática envolvendo professores e futuros professores que ensinam Matemática na educação básica, se constituiu em um aspecto fundamental na formação dos diferentes sujeitos. O episódio a seguir apresenta relatos dos membros do grupo Obeduc, núcleo PUC-SP, a respeito do questionamento feito sobre que fatores mantêm os membros do grupos unidos.

PAI2: Eu acho que o que mais nos une é a vontade de aprender, de melhorar, de qualificaro que já fazemos, porque estamos em uma Universidade, aí eu digo por mim, eu quero achar a coerência entre teoria e prática, e eu acho que o nosso grupo do Obeduc vem contemplando isso, principalmente pelos estudos e pelas discussões que nós temos aqui, por ouvirmos a prática do outro e falarmos da nossa própria prática, tudo isso contribui para melhorarmos nossas aulas de Matemática.

AP3: Acho que o que mais nos une é o compartilhamento de experiências, o que o grupo acaba passando para nós. Eu estou aprendendo bastante, está me incentivando a pesquisar e buscar cada vez mais.

PAF2: Eu acho que, até discordando um pouco da PAI2, o que nos traz aqui é a evolução profissional sim, mas o que verdadeiramente une nosso grupo é a maneira como ele é administrado e a afetividade que foi aqui desenvolvida. Eu não venho aqui por uma obrigação, porque eu tenho que estudar. Eu venho porque eu gosto, o grupo é legal, eu converso com as pessoas, é um grupo agradável pra mim. O clima que foi gerado aqui. Acho que é a primeira vez que eu vejo um grupo deste tipo que a gente faz as coisas por gosto, não só pelo conhecimento. Você vem para encontrar as pessoas, conversar, e mesmo com visões diferentes, trajetórias diferentes, isso não importa, isso não gera atritos no grupo. Se eu tenho um conhecimento que outras pessoas não têm, elas aprendem com isso, sem problema nenhum, e eu aprendo com elas. Acho que a afetividade é um diferencial muito grande neste grupo, como ele é conduzido, não é aquela coisa imposta, 'vocês têm que fazer', 'estamos pagando pra vocês, então vocês têm que fazer isto', nada é imposto aqui, a gente vai e corre atrás, se tem que pesquisar, a gente pesquisa pela nossa vontade. As coisas são decididas entre nós. Então, a maneira como o grupo é administrado é o que mais une o grupo. AM3: Eu acho que este grupo faz com que a gente mude mesmo. Eu dou aula há pouco tempo, mas minhas primeiras aulas são totalmente diferentes das aulas que eu dou agora, são diferentes porque, por incrível que pareça, eu achava que eu não dava aulas tradicionais, mas eu sou bem tradicional, e eu estou aprendendo a não ser tradicional, eu ainda não consigo, mas eu acredito que o que une o grupo são as mudanças que ele nos provoca quanto ao ensino da Matemática (ENCONTRO 07/12/2013).

Assim, podemos destacar que a prática desenvolvida pela comunidade possibilitou momentos de reflexão e de discussão, o compartilhamento de experiências, a criação de vínculos afetivos e de respeito mútuo, bem como traços de desenvolvimento profissional e de constituição da identidade de professor. Além disso, segundo relatos de professores e 
estudantes, melhoria na qualidade das práticas de sala de aula de Matemática. Resultados semelhantes também são encontrados em outros estudos que investigam Comunidades de Prática, como apontado por Rodrigues e Cyrino (2015).

Ainda, as falas elencadas evidenciam que o grupo Obeduc, núcleo da PUC-SP, de fato se constituiu em uma Comunidade de Prática, pois não somente compartilham de um interesse comum, uma paixão, como estão engajados em interagir e compartilhar saberes. Interação a partir da qual decorreram aprendizagens que são, ao mesmo tempo, individuais e coletivas.

Por esse motivo, defendemos que os resultados de nosso estudo podem ser um indicativo para as políticas públicas de formação de professores quanto à potencialidade de espaços semelhantes aos grupos do Obeduc, como uma alternativa para o desenvolvimento profissional de professores e futuros professores, na contramão de ações de formação pautadas no modelo de cursos de treinamento e palestras, marcadas muitas vezes pela ausência de situações que oportunizem o compartilhamento de experiências entre os professores.

\section{Referências}

BELINE, W. Formação de professores de matemática em comunidades de prática: um estudo sobre identidades. 2012. 312 f.. Tese (Doutorado em Ensino de Ciências e Educação Matemática) Centro de Ciências Exatas, Universidade Estadual de Londrina, Londrina, 2012.

BRASIL. Ministério da Educação. Secretaria de Educação Fundamental. Parâmetros Curriculares Nacionais: Matemática ( $1^{\circ}$ e $2^{\circ}$ ciclos do ensino fundamental). Brasília: MEC, 1997.

BRASIL. Ministério da Educação. Secretaria de Educação Fundamental. Parâmetros Curriculares Nacionais: Matemática (3 e $4^{\circ}$ ciclos do ensino fundamental). Brasília: MEC, 1998.

CYRINO, M. C. C. T. Comunidades de Prática de professores como espaço de investigação sobre formação de professores de matemática. In: BATISTA, I. L.; SALVI, R. F. Pós-Graduação em Ensino de Ciências e Educação Matemática: perfil de pesquisas. Londrina: EDUEL, 2009, p. 95 110 .

DANTE, L. R. Didática da Resolução de Problemas de Matemática. São Paulo: Ed. Ática, 2002.

FIORENTINI, D. Pesquisar práticas colaborativas ou pesquisar colaborativamente? In: BORBA, M. C. \& ARAÚJO, J. L. Pesquisa qualitativa em Educação Matemática. Belo Horizonte: Autêntica, 2004.

FIORENTINI, D.; LORENZATO, S. Investigação em educação matemática: percursos teóricos e metodológicos. 3 ed. Campinas: Autores Associados, 2012.

LAVE, J.; WENGER, E. Situated Learning: Legitimate peripheral participation. Cambridge: Cambridge University Press, 1991.

MOSER, A. Formação docente em Comunidades de Prática. Revista Intersaberes, Curitiba, ano 5, n. 10, p. 210-244, jul./dez., 2010. 
NAGY, M. C. Trajetórias de aprendizagens de professoras que ensinam matemática em um Comunidade de Prática. 197 f. Tese (Doutorado em Ensino de Ciências e Educação Matemática) Universidade Estadual de Londrina, Londrina, 2013.

ONUCHIC, L. R. Ensino-aprendizagem de Matemática através da Resolução de Problemas. In: BICUDO, M. A.V. (Org.) Pesquisa em Educação Matemática: concepções \& perspectivas. São Paulo: Unesp Editora, 1999. p. 199-218.

POLYA, G. A arte de resolver problemas. Trad. e adapt. Heitor Lisboa de Araújo. Rio de Janeiro: Interciência, 1978.

RAMOS, W. R., Observatório da Educação da PUC-SP e a formação de professores que ensinam matemática em Comunidades de Prática. 2015. 127 f. Dissertação (Mestrado em Educação Matemática) - Faculdade de Ciências Exatas e Tecnologia, Pontifícia Universidade Católica de São Paulo, São Paulo, 2015.

RODRIGUES, P. H.; CYRINO, M.C.C.T. Pesquisas do GEPEFOPEM e o desenvolvimento profissional de professores que ensinam matemática em Comunidades de Prática. In: III SIMPÓSIO NACIONAL DE GRUPOS COLABORATIVOS E DE APRENDIZAGEM DO PROFESSOR QUE ENSINA MATEMÁTICA, 2015, São Paulo. Anais... São Paulo: UNICID, 2015. v. 1. p. 1-12.

SILVA, S. C. R.; SCHIRLO, A. C. Discutindo as práticas de ensino: Resolução de Problemas e Investigação Matemática. Revista Eletrônica Debates em Educação Científica e Tecnológica, Vitória, v. 04, n. 01, p. 52 - 51, junho, 2014.

VIANNA, H. M. Pesquisa em educação: a observação. Brasília: Líber Livro Editora, 2007 (Série Pesquisa, v. 5).

WENGER, E. Comunidades de Práctica: Aprendizaje, significado e identidad. Barcelona: Paidós, 2001.

WENGER, E. Knowledge management as a doughnut: shaping tours knowledge strategy through communities of practice. Ivey Business Journal, London, v. 68, n. 3, p. 1-8, January/February, 2004.

WENGER, E.; MCDERMOTT, R.; SNYDER, W. M. Cultivating Communities of Practice: a guide to managing knowledge. Boston: Harvard University Press, 2002.

Submetido em Abril de 2015. Aprovado em Setembro de 2015. 